\title{
Recent Advances in Multiband Printed Antennas Based on Metamaterial Loading
}

\author{
F. Paredes, ${ }^{1}$ G. Zamora, ${ }^{1}$ S. Zufanelli, ${ }^{1}$ F. J. Herraiz-Martínez, ${ }^{2}$ J. Bonache, ${ }^{1}$ and F. Martín ${ }^{1}$ \\ ${ }^{1}$ GEMMA/CIMITEC, Departament d'Enginyeria Electrònica, Universitat Autònoma de Barcelona, 08193 Barcelona, Spain \\ ${ }^{2}$ Departamento de Teoría de la Señal y Comunicaciones, Universidad Carlos III, 28911 Madrid, Spain \\ Correspondence should be addressed to F. Martín, ferran.martin@uab.es
}

Received 16 May 2012; Accepted 9 July 2012

Academic Editor: Ivan D. Rukhlenko

Copyright ( 2012 F. Paredes et al. This is an open access article distributed under the Creative Commons Attribution License, which permits unrestricted use, distribution, and reproduction in any medium, provided the original work is properly cited.

\begin{abstract}
It is shown that printed antennas loaded with metamaterial resonators can be designed to exhibit multiband functionality. Two different antenna types and metamaterial loading are considered: (i) printed dipoles or monopoles loaded with open complementary split ring resonators (OCSRRs) and (ii) meander line or folded dipole antennas loaded with split ring resonators (SRRs) or spiral resonators (SRs). In the first case, multiband operation is achieved by series connecting one or more OCSRRs within the dipole/monopole. Such resonators force opens at their positions, and by locating them at a quarter wavelength (at the required operating frequencies) from the feeding point, it is possible to achieve multiple radiation bands. In the second case, dualband functionality is achieved through the perturbation of the antenna characteristics caused by the presence of the metamaterial resonators. This latter strategy is specially suited to achieve conjugate matching between the antenna and the chip in radiofrequency identification (RFID) tags at two of the regulated UHF-RFID bands.
\end{abstract}

\section{Introduction}

Metamaterials are effective media made of periodic (or quasiperiodic) inclusions of conventional materials (typically metals and dielectrics) with controllable acoustic, electromagnetic, or optical properties. Indeed, by properly structuring these artificial materials, it is possible to achieve unique and exotic properties, such as negative refraction or subwavelength focusing, among others, and it is potentially possible to implement acoustic and optical cloaks. There has been an intensive research activity in this field since 2000 [1-10], when the first metamaterial structure by Smith and co-workers was reported [11]. Key to the success of this research field was the synthesis of negative effective permeability media by means of split ring resonators (SRRs) [12]. These particles are electrically small resonators that can be excited by means of an axial magnetic field. Hence, if an array of SRRs is illuminated by means of an electromagnetic radiation with the magnetic field axial to the SRRs, the structure behaves as an effective medium with negative permeability in a narrow band above SRR resonance. By combining SRRs with metallic posts (exhibiting a negative effective permittivity up to the so-called plasma frequency), the first structure simultaneously exhibiting negative permittivity and permeability was synthesized [11]. These structures are called left-handed, or double negative, materials, and the main relevant feature of such media, derived from the negative sign of the constitutive parameters, is the antiparallelism between the phase and group velocities [13].

The metamaterial concept and some metamaterial properties were soon transferred to the microwave engineering field, since it was demonstrated that by loading a transmission line with series capacitances and shunt inductances, lefthanded wave propagation (i.e., backward waves) is achieved [14-16]. These artificial lines loaded with series capacitances and shunt inductances and exhibiting some metamaterial properties are called metamaterial transmission lines. In 2003, it was demonstrated that metamaterial transmission lines can also be implemented by means SRRs [17]. Specifically, by properly combining SRRs and shunt strips in a coplanar waveguide (CPW) transmission line, backward wave propagation in a narrow band arises, and by merely loading the CPW with SRRs, the structure exhibits a stopband behavior that has been interpreted as due to the 

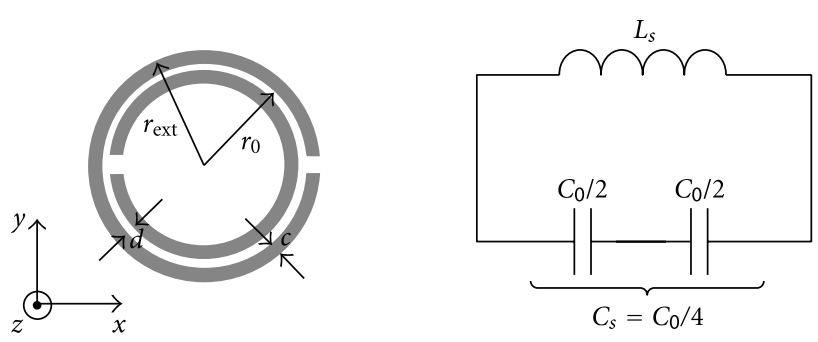

(a)
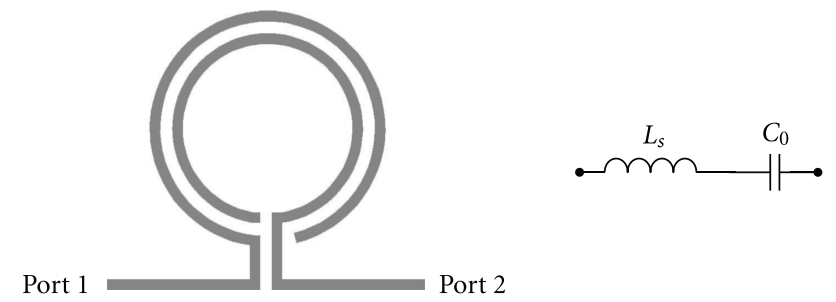

(c)
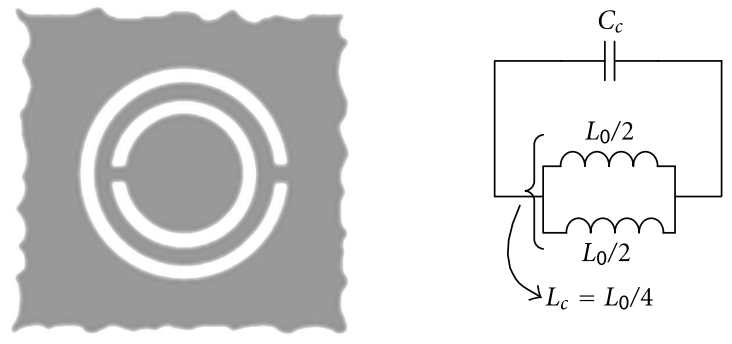

(b)

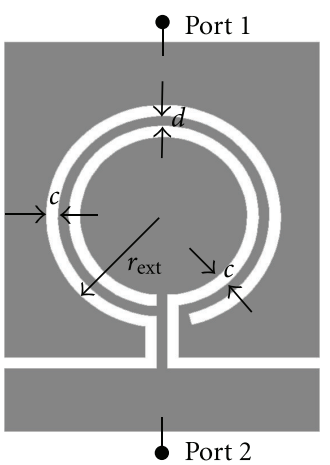

(d)

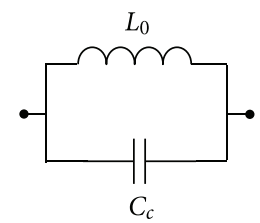

FIGURE 1: Typical topology and lumped element equivalent circuit model of the (a) SRR, (b) CSRR, (c) OSRR, and (d) OCSRR.

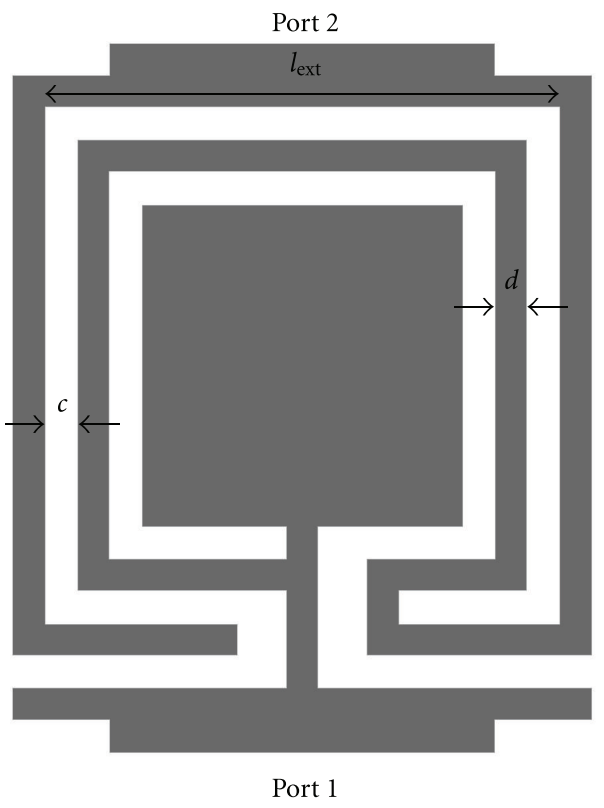

(a)

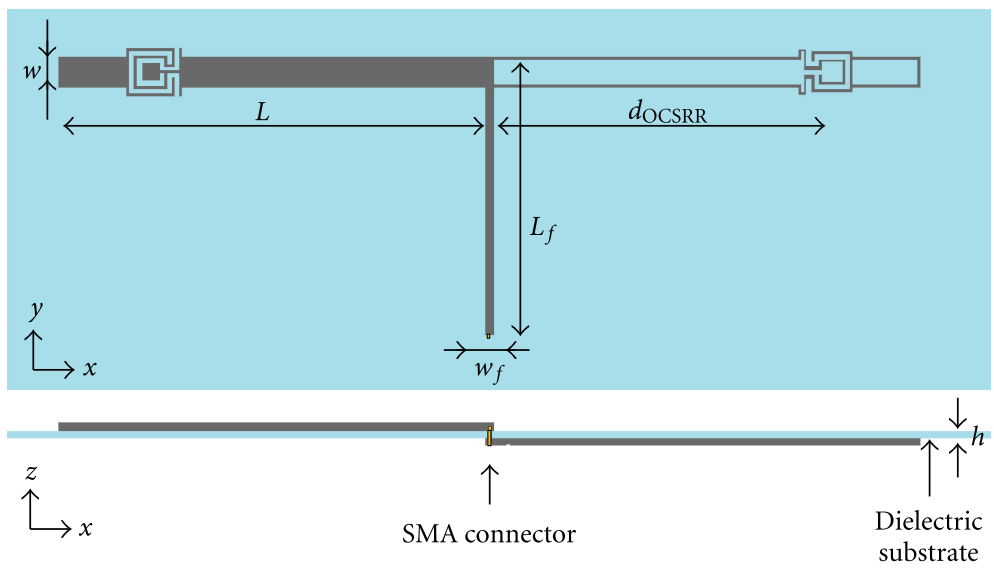

(b)

FIGURE 2: Sketch of the antipodal dipole antenna. (a) Topology of the square-shaped OCSRR. (b) Top and cross-sectional views of the dipole antenna loaded with OCSRRs.

negative value of the effective permeability in the stop band [18]. It is important to mention that even though effective permeability and permittivity in metamaterial transmission lines can be defined $[1,2,4]$, the relevant parameters in transmission lines (fundamental for design purposes) are the phase constant and the characteristic impedance. Thanks to the presence of reactive elements (inductances, capacitances, or electrically small resonators) in metamaterial transmission lines, it is possible to tailor these parameters to some extend in these artificial lines. Therefore, the key advantage of metamaterial transmission lines over conventional lines is the controllability of the phase constant and characteristic 
impedance [19]. In many applications few (or even a single) unit cells suffice to achieve the required line specifications. Hence, periodicity and homogeneity (necessary for the implementation of effective media metamaterials) are not a due in metamaterial transmission lines. Indeed, some times, rather than tailoring the characteristic impedance or the phase of a transmission line, it might be simply necessary to use coupled resonators in order to achieve a transmission zero or to perturb somehow the line characteristics in the vicinity of particle resonance. As long as the considered resonators are electrically small and related to the SRR, these resonator-loaded lines are called transmission lines with metamaterial loading. This concept can be made extensive to other structures such as printed antennas, which is the case considered in this paper.

The paper is organized as follows. In Section 2, the metamaterial resonators considered in this paper are reviewed. Section 3 is focused on multiband printed dipole and monopole antennas loaded with open complementary split ring resonators (OCSRRs), and Section 4 is devoted to the implementation of dual-band UHF-RFID tags based on meander line and folded dipole antennas with metamaterial loading. Finally the main conclusions are highlighted in Section 5.

\section{SRRs and Other Related Metamaterial Resonators}

The typical topology of the SRR is depicted in Figure 1(a). It consists on a pair of coupled split rings with the apertures on opposite sides. The coupling between both rings drives the first resonance frequency to low values, as compared to that of the individual rings, and for this reason the SRR is electrically small. By virtue of the small electrical size of the particle, a quasistatic analysis can be applied to the SRR $[4,20]$, and the capacitance and inductance are given by the series connection of the distributed (edge) capacitances of both SRR halves and by the inductance of a single loop of identical width $c$ and average radius $r_{0}$. Pairs of SRRs etched in the back substrate side of CPW transmission lines can be inductively driven by the magnetic field generated by the line, resulting in negative effective permeability metamaterial transmission lines [17, 18].

By applying duality, the complementary split ring resonator (CSRR) results $[21,22]$ (Figure $1(\mathrm{~b})$ ). This resonator exhibits roughly the same resonance frequency to that of the SRR (provided the same dimensions and substrate are considered) and is typically driven by an axial time-varying electric field. CSRRs have been used for the implementation of negative effective permittivity metamaterial transmission lines in microstrip technology, where the CSRRs are etched in the ground plane beneath the conductor strip (more details on the calculation of particle inductance and capacitance are given in [23]).

Let us now consider the open versions of the previous particles, that is, the open SRR (OSRR) [24] and the open CSRR (OCSRR) [25]. The typical topologies are depicted in Figures $1(\mathrm{c})$ and $1(\mathrm{~d})$, respectively. Notice that as long

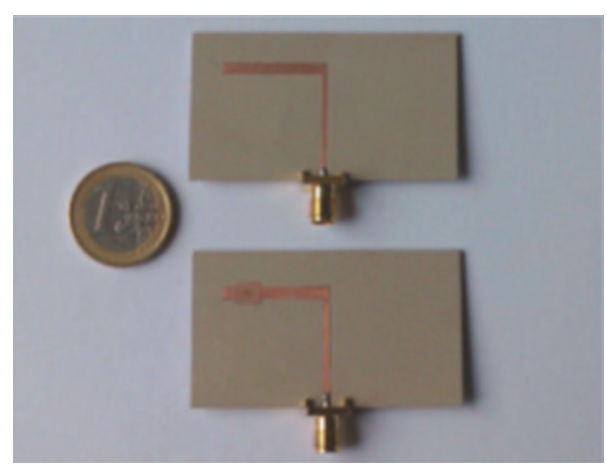

FIgURE 3: Picture of the fabricated prototypes. Top: unloaded printed dipole antenna. Bottom: proposed dual-band printed dipole antenna.

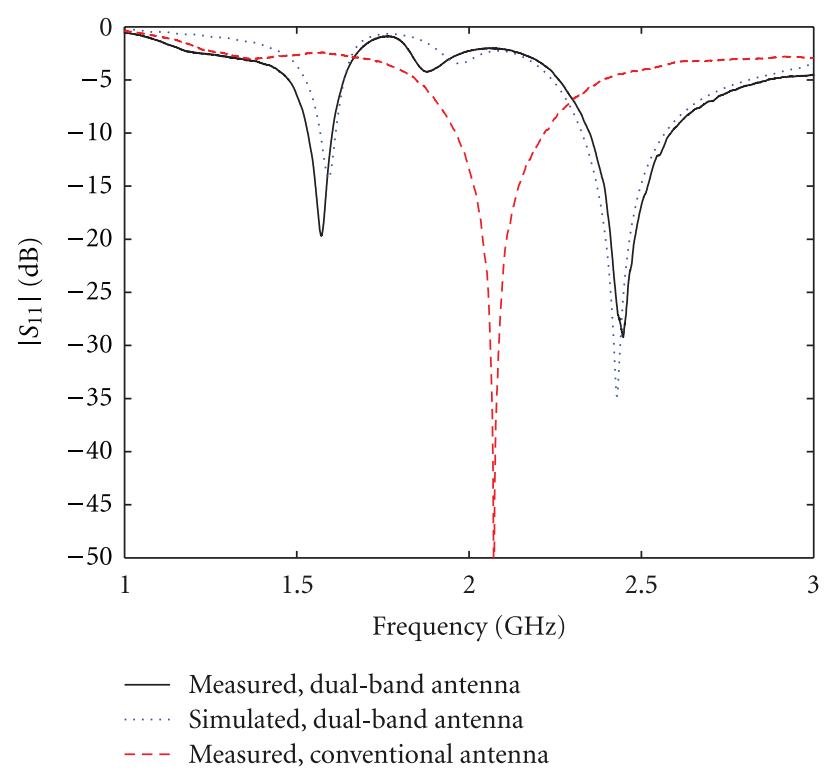

FIGURE 4: Measured and simulated reflection coefficient of the proposed dual-band antenna compared to the unloaded antenna. (-) measured dual-band printed dipole antenna; (- - - -) simulated dual-band printed dipole antenna; (_ - ) measured unloaded printed dipole antenna.

as these particles are open resonators (the connecting pins are indicated), they can be excited by means of a voltage or a current source. As compared to SRRs and CSRRs, OSRRs and OCSRRs are electrically smaller by a factor of two. The reason is simple: for the OSRR, the inductance is identical to that of the SRR, but the capacitance is the edge capacitance of the whole circumference, and hence it is 4 times higher than that of the SRR. This reduces the resonance frequency of the OSRR to half the resonance frequency of the SRR. For the OCSRR, the capacitance is identical to that of the CSRR, but the inductance is four times larger since in the CSRR there are two inductive paths (in parallel) between the inner region of the particle and the outside metallic region, whereas for the OCSRR there is a single inductive path corresponding to the whole circumference of the particle. As can be seen 


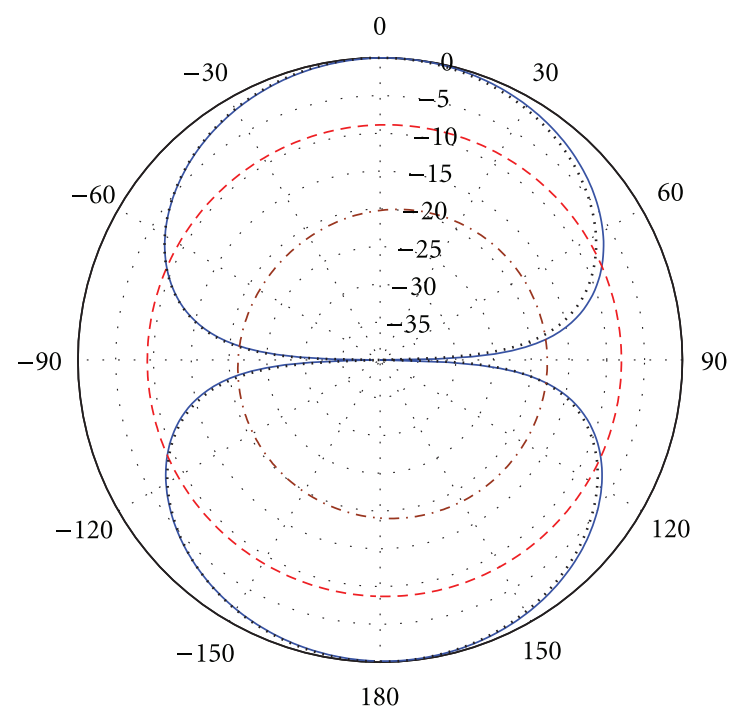

(a)

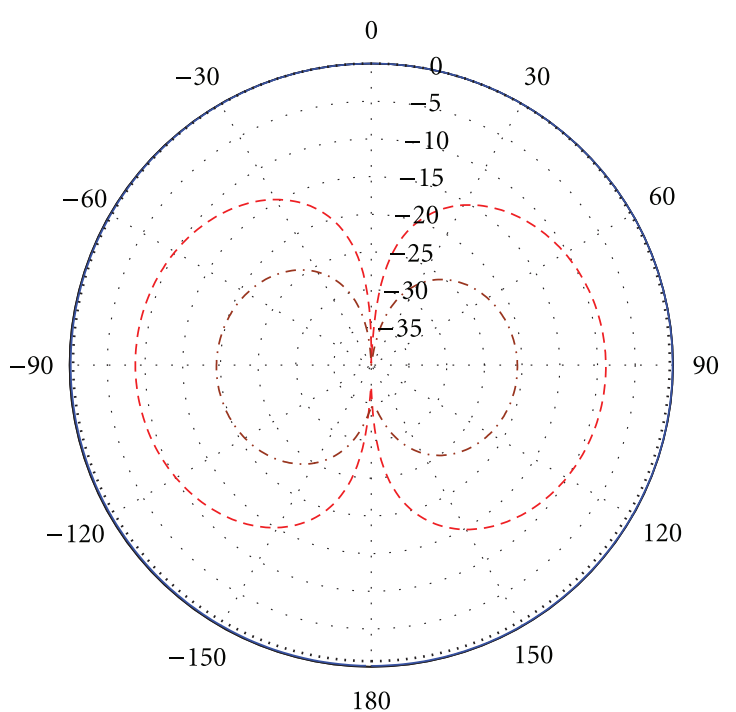

(b)

FIGURE 5: Simulated normalized radiation patterns for the dual-band dipole antenna. (a) XZ plane. (b) YZ plane. (—-) $1.575 \mathrm{GHz}$ (copolar component); ( — —); $1.575 \mathrm{GHz}$ (cross-polar component); (- - -) $2.45 \mathrm{GHz}$ (copolar component); (—- - $2.45 \mathrm{GHz}$ (crosspolar component).

in the circuit models depicted in Figure 1, the OSRR is an open series resonator, whereas the OCSRR is an open parallel resonator. It has been demonstrated that combined OSRRs and OCSRR in CPW and microstrip lines are useful for the implementation of metamaterial transmission lines (and many circuits based on them) and broadband bandpass filters [26].

By connecting the external pins of the OSRR, a 2-turn spiral resonator (2-SR) results [27, 28] (other multiple-turn spirals have been studied in the literature [29]). Therefore the 2-SR is a closed resonator that exhibits the same resonance frequency as that of the OSRR. It can also be concluded from duality arguments that the complementary counterpart of the 2-SR exhibits also this resonance frequency (which is also that of the OCSRR).

\section{Multiband Printed Dipole and Monopole Antennas with Metamaterial Loading}

Let us now focus on the design of antennas loaded with metamaterial resonators. Indeed, the improvement of antenna performance by means of metamaterials has been a subject of intensive research in recent years. Metamaterial substrates and superstrates to improve the antenna directivity in planar antennas, or leaky wave antennas with scanning capability based on metamaterial transmission lines, are two of the multiple applications of metamaterial technology in the field of antennas [1-5, 30-33] (an in-depth review of this topic is out of the scope of this paper).

In this section, the focus is on metamaterial-loaded printed antennas [34-36]. The idea of this technique is based on loading a conventional printed antenna with a set of resonant particles. For example, in [34], it is shown that a dual-band antenna is achieved by coupling a set of SRRs to a printed dipole. Using this approach, the benefits of printed antennas are kept while dual-band antennas are achieved by using a simple design technique. The SRRs produce open circuits in their positions at the resonance frequencies. Hence the antenna resonance is achieved not only when the effective length of the dipole arms is $\lambda / 4$ ( $\lambda$ being the guided wavelength), but also when the different locations of the SRR are $\lambda / 4$ from the antenna feeding point (the SRRs must be tuned at these frequencies). By using SRRs, narrow bandwidths are reported in [34] for the bands associated with the SRR loading. Even the use of SRRs with different resonance frequencies leads to bandwidths smaller than 5\% [35], which might not be useful for most applications. However, an open circuit in the dipole arms can also be obtained by means of OCSRRs. The advantage is that by series connecting OCSRRs within the dipole, broadband responses can be achieved (as compared to SRRs), due to the relative values of capacitance and inductance.

To illustrate the potential of OCSRR-loaded printed antennas, we report here a dual-band dipole [37] and a tri-band monopole [38]. The layout of the printed dipole (an antipodal structure) and the details of the OCSRR are depicted in Figure 2, whereas the photograph of the antenna is shown in Figure 3, and compared to the conventional monoband dipole. The parameters of each dipole strip are the length $L$ and the width $W$ (which must be engineered to optimize matching). This configuration has been chosen because it avoids the use of a balun to feed the antenna. This is possible because the antipodal printed dipole is fed through a paired strips transmission line with a SMA connector soldered to the end of the line. The dimensions of the feeding line are the length $L_{f}$ and the width $W_{f}$. An OCSRR is connected in series to each dipole strip at 


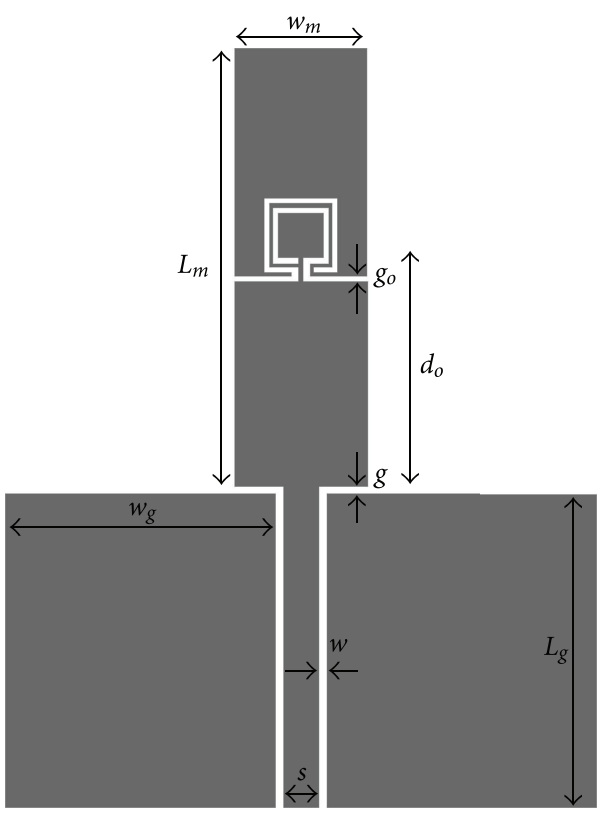

(a)

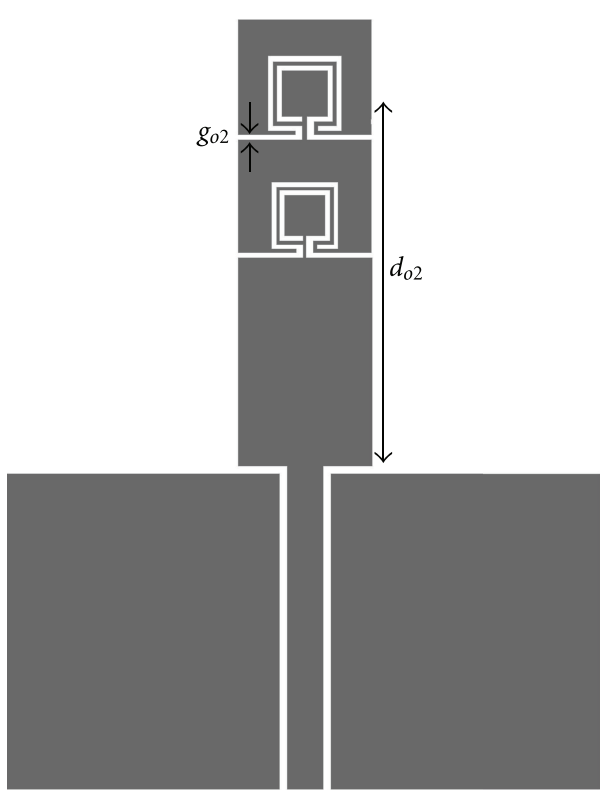

(b)

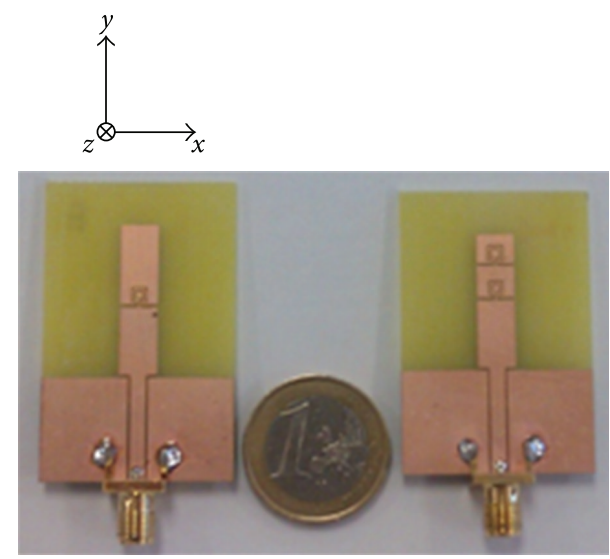

(c)

FIGURE 6: Sketch of the proposed dual-band (a), and triband (b) printed monopole antenna loaded with OCSRRs, and respective photographs (c).

a distance $d_{\text {OCSRR }}$ from the center of the antenna. The different dimensions of the proposed antenna have been optimized to simultaneously operate at the L1-GPS frequency $(1.575 \mathrm{GHz})$ and the WiFi band of $2.4-2.48 \mathrm{GHz}$. The final dimensions of the design are $L=22.00 \mathrm{~mm}, W$ $=2.50 \mathrm{~mm}, L_{f}=25.00 \mathrm{~mm}, W_{f}=1.15 \mathrm{~mm}, d_{\text {OCSRR }}=$ $17.00 \mathrm{~mm}, l_{\text {ext }}=4.00 \mathrm{~mm}$, and $c=d=0.30 \mathrm{~mm}$. The used substrate is the Rogers RO3010 with $\varepsilon_{r}=10.2$ and $h=$ $1.27 \mathrm{~mm}$.

In the case of the conventional unloaded antenna, there is only one series resonance within the band of interest. This resonance frequency is $2.2 \mathrm{GHz}$. This resonance corresponds to the fundamental mode of the dipole antenna. Moreover, in the vicinity of the resonance, the value of the real part of the impedance is close to $50 \Omega$ (not shown), which produces proper matching, as it can be observed in Figure 4. On the other hand, the OCSRR loading introduces a parallel resonance in the proposed dual-band antenna input impedance. The addition of this parallel resonance has a double effect on the input impedance of the proposed dual-band antenna. The first one is a slight shift on the series resonance of the dipole antenna towards higher frequencies. In this case, this resonance is found at $2.45 \mathrm{GHz}$. The second effect is the appearance of an additional series resonance below the parallel resonance of the OCSRRs. This additional series resonance is found at $1.6 \mathrm{GHz}$. The real part of the input impedance is around $50 \Omega$ in the vicinity of this additional series resonance. This allows achieving an additional band with proper matching in the proposed antenna (Figure 4). As it can be seen, this additional frequency is below the fundamental frequency of the unloaded dipole antenna, achieving some degree of miniaturization. 


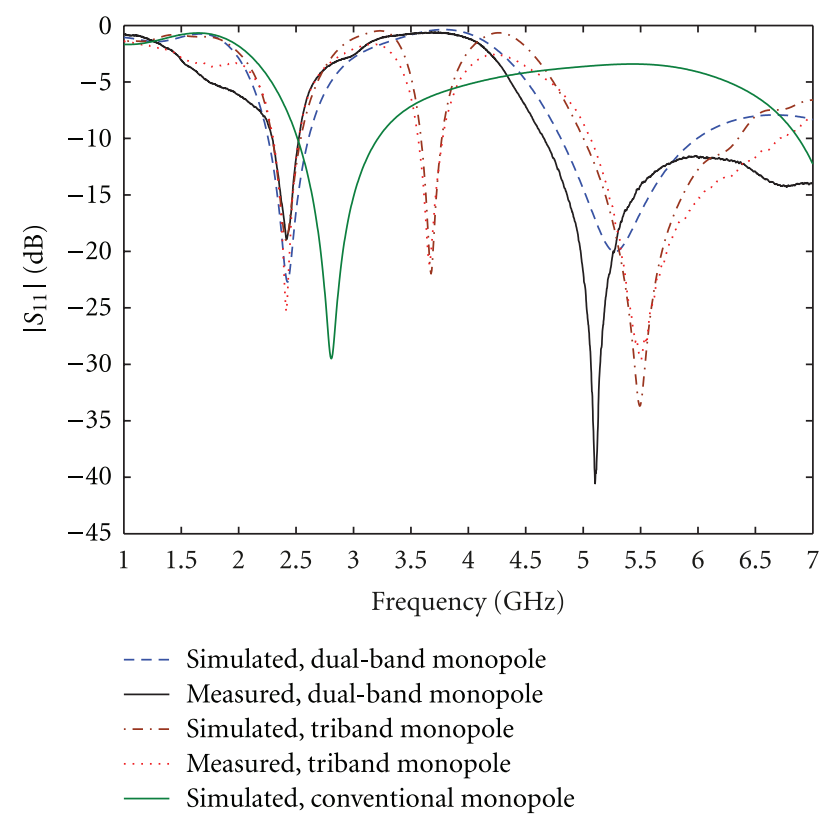

Figure 7: Simulated and measured reflection coefficient of the proposed dual-band and tri-band printed monopole antennas. The simulated reflection coefficient of the conventional monopole antenna is also plotted.

Considering $\left|S_{11}\right|$ below $-10 \mathrm{~dB}$, the first working band is centered at $1.56 \mathrm{GHz}$ with $5 \%$ bandwidth and the second one is centered at $2.46 \mathrm{GHz}$ with $9 \%$ bandwidth. It is important to note that this is a considerable improvement with respect to other works in which the bandwidth of one of the bands was always below 5\% [34, 35]. The obtained results cover the bandwidth of the proposed applications (GPS and WiFi). The gain of the antenna has been estimated in a TEM cell from the power received by the antenna and the incident field measured by a probe [39]. The measured gain of the proposed antenna is $0.85 \mathrm{~dB}$ at the GPS band $(1.575 \mathrm{GHz})$ and $2 \mathrm{~dB}$ at the WiFi band $(2.45 \mathrm{GHz})$. These experimental results agree with the CST-simulated ones: $0.9 \mathrm{~dB}$ at the first band and $2.2 \mathrm{~dB}$ at the second one.

The CST-predicted radiation patterns for the proposed dual-band antenna are shown in Figure 5 for completeness. A dipolar-like radiation pattern is obtained at both working bands. The typical figure of eight is obtained in the $X Z$ plane and an omnidirectional pattern is obtained in the $Y Z$ plane at both frequencies $(1.575$ and $2.45 \mathrm{GHz}$ ). The only difference between both working bands is the cross-polarization level, which is around $-10 \mathrm{~dB}$ in the first band while it is $-20 \mathrm{~dB}$ in the second one.

Following the ideas of the antipodal dipole antennas with metamaterial loading, we have also designed multiband printed monopole antennas. Figure 6 shows a photograph of two fabricated prototypes: a dual band and a tri-band printed monopole. The considered substrate in this case is the low-cost FR4 $\left(\varepsilon_{r}=4.5\right.$ and $\left.h=1.5 \mathrm{~mm}\right)$. The dualband antenna covers the bands of $2.40-2.48 \mathrm{GHz}$ (Bluetooth and $\mathrm{WiFi}$ ) and 5.15-5.80 GHz (WiFi). The final dimensions of the monopole are $L_{m}=21 \mathrm{~mm}, W_{m}=5.85 \mathrm{~mm}$. The parameters of the feeding line are set to obtain a $50 \Omega \mathrm{CPW}$.
Hence, $S=2.44 \mathrm{~mm}$ and $W=0.30 \mathrm{~mm}$. The dimensions of each ground plane are $L_{g}=16 \mathrm{~mm}$ and $W_{g}=13.48 \mathrm{~mm}$. The gap between the ground planes and the monopole is $g=$ $0.30 \mathrm{~mm}$. The OCSRR is placed at a distance $d_{o}=12.50 \mathrm{~mm}$ and its parameters are $l_{\text {ext }}=2.30 \mathrm{~mm}, c=d=0.25 \mathrm{~mm}$. The gap $g_{o}$ is set to $0.50 \mathrm{~mm}$.

The tri-band monopole antenna is an extension of the previous dual-band antenna and it covers the previous bands and the IEEE $802.11 \mathrm{y}$ band of $3.65-3.70 \mathrm{GHz}$. According to the layout of the tri-band monopole (Figure 6), the additional OCSRR is placed at a distance $d_{o 2}=18.00 \mathrm{~mm}$. Its design parameters are $l_{\mathrm{ext}}=2.70 \mathrm{~mm}, c=d=0.25 \mathrm{~mm}$. This corresponds to a resonance frequency of $3.65 \mathrm{GHz}$. The gap $g_{o 2}$ is set to $0.40 \mathrm{~mm}$. These values have been optimized to only cover the desired bandwidth and not interfere with other systems. The other parameters of the antenna remain unchanged with respect to the dual-band design, except the length of the monopole which is reduced to $L_{m}=19.75 \mathrm{~mm}$ to compensate the inductive behavior of the OCSRRs below their resonance frequencies.

The simulated and measured reflection coefficients of the dual-band and tri-band monopoles are depicted in Figure 7. The dual-band printed monopole antenna exhibits good matching $\left(\left|S_{11}\right|<-10 \mathrm{~dB}\right)$ from $2.29 \mathrm{GHz}$ to $2.52 \mathrm{GHz}$ at the lower frequency band. This corresponds to a $9.6 \%$ bandwidth. In the upper band, the antenna is well matched from $4.66 \mathrm{GHz}$ to at least $7 \mathrm{GHz}$. Thus, the fabricated antenna satisfies the specifications of Bluetooth and WiFi (bands of $2.40-2.48 \mathrm{GHz}$ and $5.15-5.80 \mathrm{GHz}$ ). The fabricated tri-band monopole antenna is well matched from $2.30 \mathrm{GHz}$ to $2.52 \mathrm{GHz}$ for the first band. Its reflection coefficient is below $-10 \mathrm{~dB}$ between $3.56 \mathrm{GHz}$ and $3.78 \mathrm{GHz}$ for the second band, and between $5.06 \mathrm{GHz}$ and $6.71 \mathrm{GHz}$ 


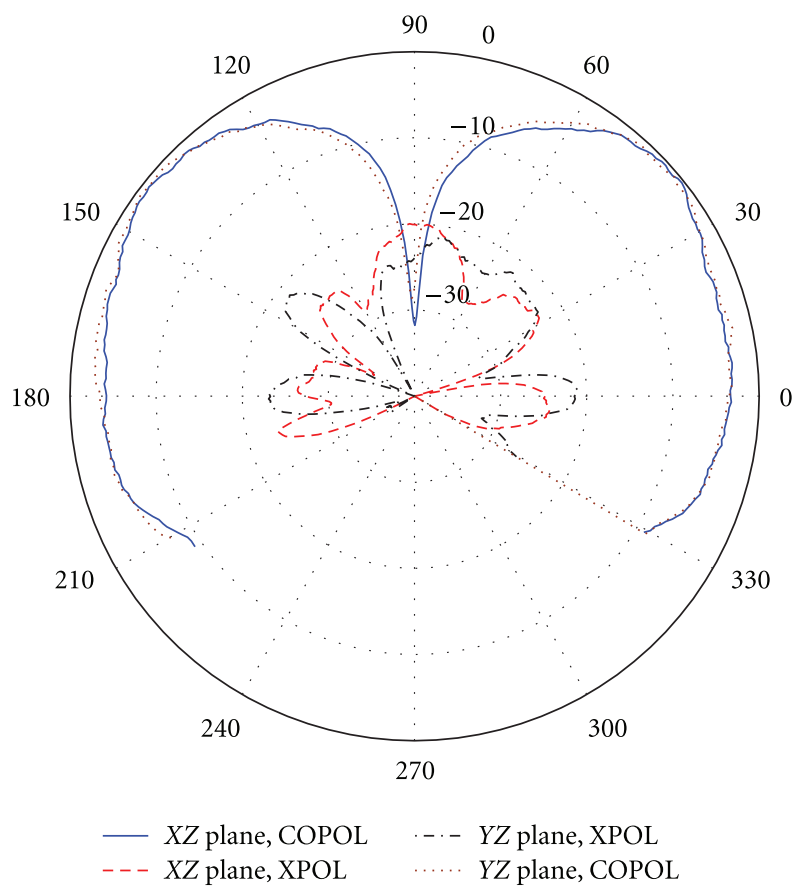

(a)

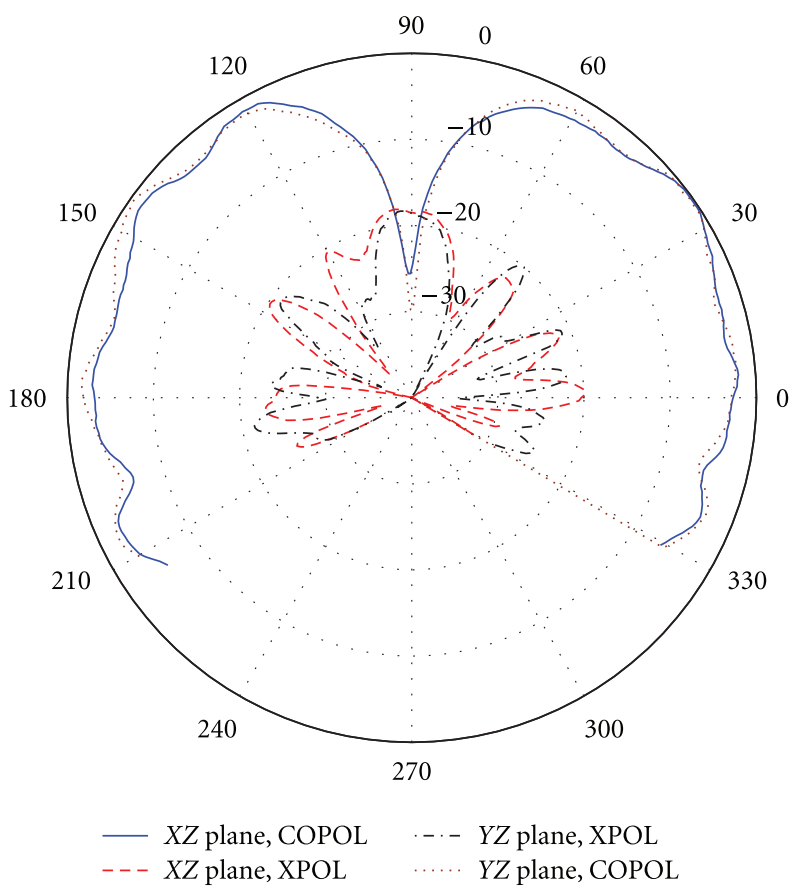

(b)

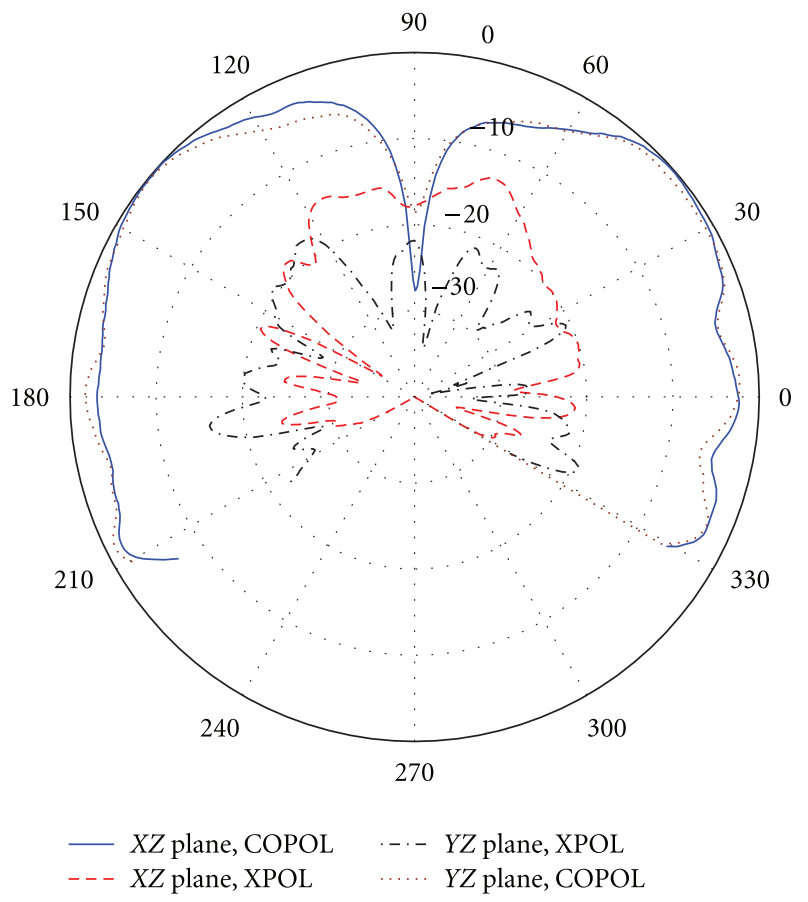

(c)

FIGURE 8: Measured radiation patterns of the tri-band printed monopole antenna. (a) $2.45 \mathrm{GHz}$, (b) $3.65 \mathrm{GHz}$, (c) $5.40 \mathrm{GHz}$.

for the third band. Hence, the fabricated prototype is well matched within the regulated bandwidths of Bluetooth and WiFi including IEEE 802.11y $(3.65-3.70 \mathrm{GHz}$ band).

The proposed antennas present monopolar radiation characteristics at all the bands. As an example, the normalized measured radiation patterns of the tri-band monopole antenna are shown in Figure 8. A monopolar radiation pattern is obtained at the three frequencies. The cross-polar component (XPOL) has low values (below $-20 \mathrm{~dB}$ in all of the cases, except the $X Y$ plane of the third frequency which is below $-15 \mathrm{~dB}$ ). The gains of this design are $1.4 \mathrm{~dB}, 1.2 \mathrm{~dB}$, and $1.7 \mathrm{~dB}$ at the first, second, and third bands, respectively. These results are in good agreement with simulations, in 


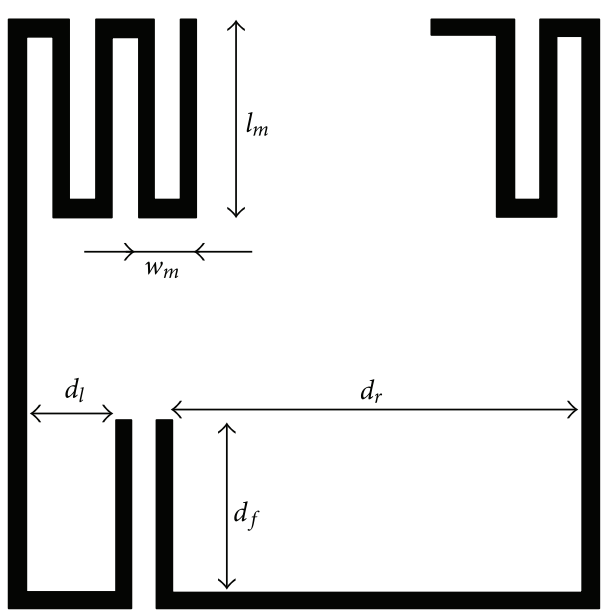

(a)

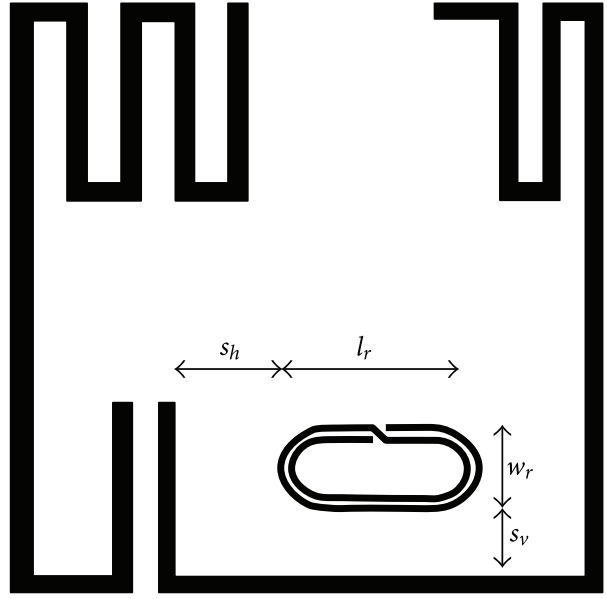

(b)

FIGURE 9: Layout of the meander line antenna considered for tag implementation (a) and layout of the MLA perturbed by the presence of a coupled two-turns spiral resonator, 2-SR (b). The strip width of the 2-SR is $0.5 \mathrm{~mm}$, and the separation between strips is $0.3 \mathrm{~mm}$.

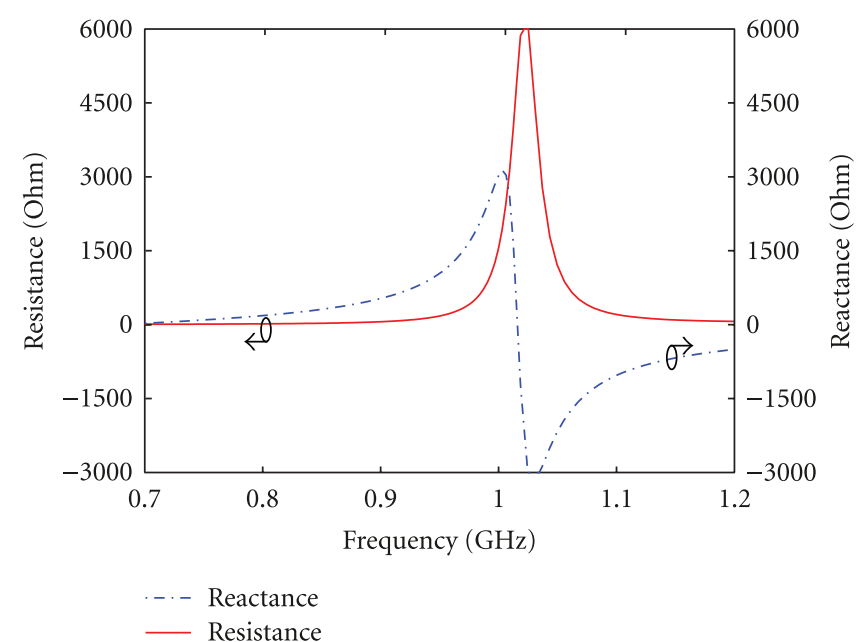

(a)

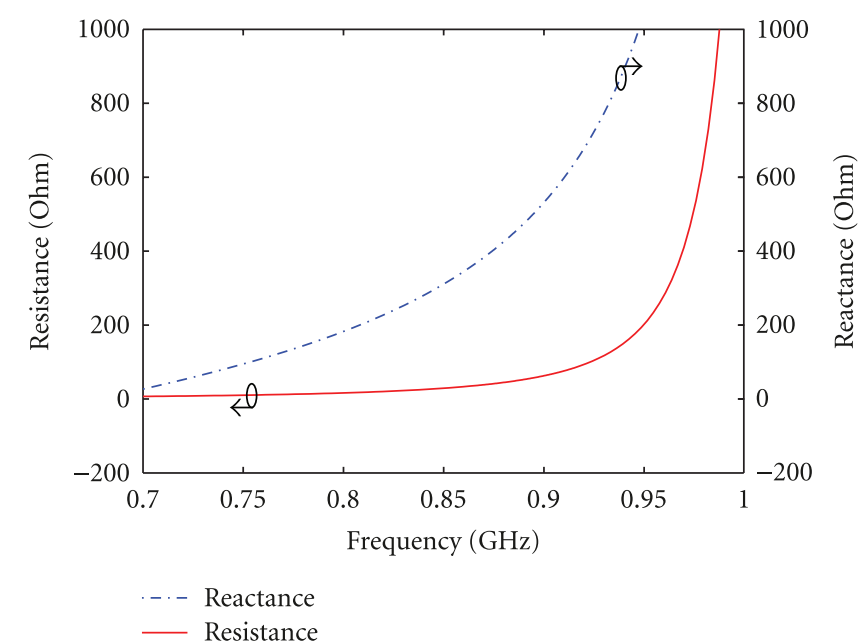

(b)

FIGURE 10: Input impedance of the MLA depicted in Figure 9(a) in a broader band (a) and input impedance of the MLA in the region of interest (b).

which the radiation efficiency is $92 \%, 83 \%$, and $94 \%$ and the overall efficiency is $91 \%, 82 \%$, and $93 \%$ at the central frequency of each band.

\section{Dual-Band UHF-RFID Tags}

Metamaterial loading is also interesting for the implementation of dual-band antennas with closed frequency bands, as is the case of UHF-RFID, where the different regulated bands worldwide are contained in the spectral region between $860 \mathrm{MHz}$ and $960 \mathrm{MHz}$. In this case, however, the approach is based on a perturbation method which was reported in [40]. The key aspect in the implementation of long read-range UHF-RFID tags is to achieve conjugate matching between the antenna and the integrated circuit (or chip). The input impedance of the chip is provided by the manufacturer and varies with frequency. Therefore, the implementation of dual-band UHF-RFID tags means to design the antenna (and the matching network, if it is present) so that the chip "sees" its conjugate impedance at the required frequencies. This can be done by cascading a dual-band impedance matching network between the antenna and the chip, consisting on a transmission line loaded with a metamaterial resonator [40]. The resonator produces a perturbation in both the characteristic impedance and the phase constant of the transmission line, and conjugate matching at two frequencies can be obtained (the details are given in [40]). However, it is possible to directly actuate on the characteristic impedance of the antenna, by loading it with metamaterial resonant particles [41] (avoiding thus the matching circuitry). The principle is very similar to that reported in [40] for matching networks. 


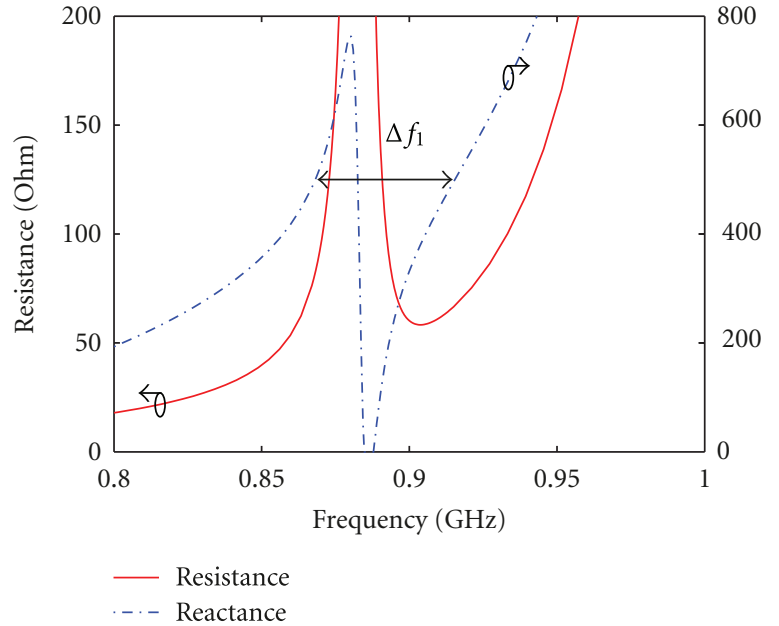

(a)

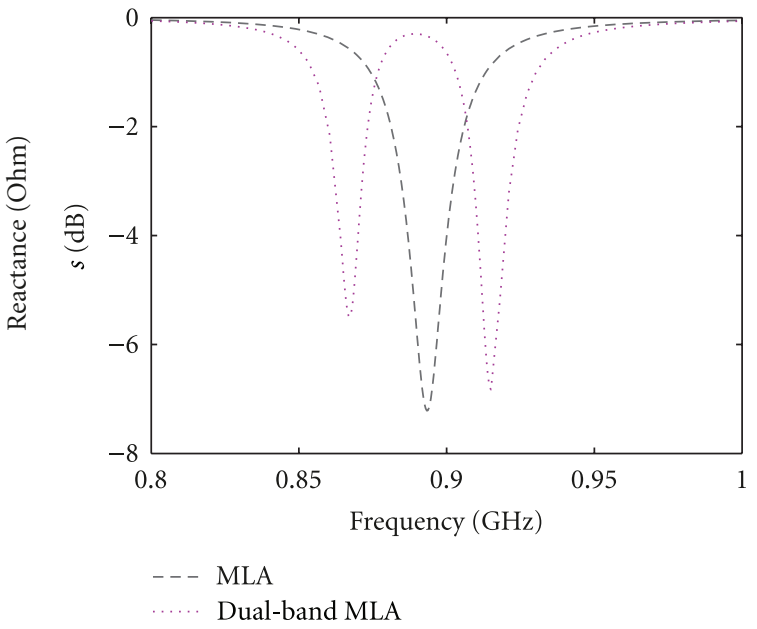

(b)

FIGURE 11: Input impedance of the dual-band MLA with coupled SR depicted in Figure 9(b) and power wave reflection coefficient of the monoband and dual-band meander line antenna. The frequencies where reactance matching is obtained, separated by $\Delta f_{1}$, are indicated and correspond to the resonance frequencies of the dual-band MLA.

Following the above-cited perturbation approach, several dual-band UHF-RFID tag antennas have been implemented. One prototype device consists on a meander line antenna (MLA) loaded with a spiral resonator (SR). The layout of the antenna, compared to the one without the SR is depicted in Figure 9. The dual-band antenna has been designed to be operative at the European $(867 \mathrm{MHz})$ and USA $(915 \mathrm{MHz})$ UHF-RFID regulated bands. The antenna has been designed on the Rogers RO3010 with dielectric constant $\varepsilon_{r}=10.2$ and thickness $h=0.127 \mathrm{~mm}$. The considered RFID chip is the SL31001 from NXP semiconductors. The impedance of the chip at the intermediate frequency is $Z_{\text {chip }}=20-\mathrm{j} 485 \Omega$. This impedance is considered as reference impedance so that the antenna is designed to roughly exhibit the conjugate impedance of the chip at this intermediate frequency, and then the perturbation (by means of the SR) is introduced in order to achieve conjugate matching at the required frequencies. The dimensions of the MLA are $48 \mathrm{~mm} \times$ $48 \mathrm{~mm}$, and the strip width is $1.4 \mathrm{~mm}$. The other relevant dimensions are $l_{m}=16.3 \mathrm{~mm}, w_{m}=4.8 \mathrm{~mm}, d_{l}=7.3 \mathrm{~mm}$, $d_{r}=33.9 \mathrm{~mm}$, and $d_{f}=14.2 \mathrm{~mm}$. The input impedance of the MLA is depicted in Figure 10, whereas Figure 11 depicts the input impedance and matching of the MLA loaded with the SR. As can be appreciated, the dual-band functionality in the SR-loaded MLA is achieved.

Both antennas have been fabricated, and the read range, given by

$$
r=\frac{\lambda}{4 \pi} \sqrt{\frac{\text { EIRPG }_{r} \tau}{P_{\text {chip }}}},
$$

has been measured through the experimental setup available in our laboratory (Figure 12). In (1), $\lambda$ is the wavelength, EIRP, determined by local country regulations, is the product of $P_{t} G_{t}$ which are the transmission power and the transmission gain, respectively, $P_{\text {chip }}$ is the minimum threshold

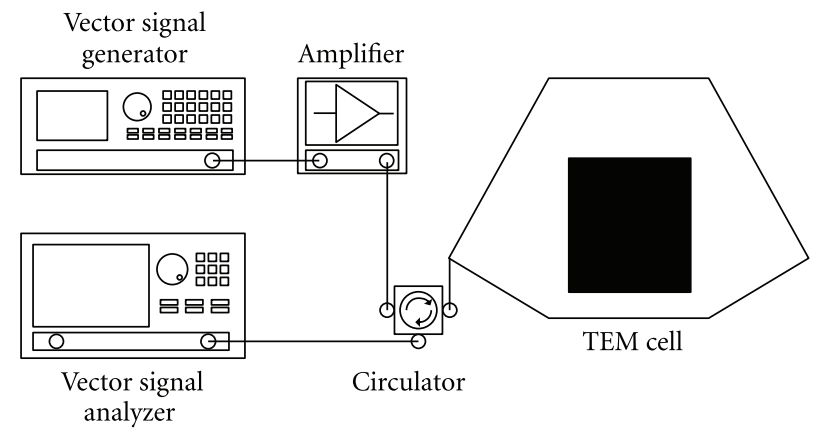

FIGURE 12: Bloch diagram of the experimental setup.

power necessary to activate the RFID chip, $G_{r}$ is the gain of the receiving tag antenna, and $\tau$ is the power transmission coefficient. The value of EIRP in European frequencies is $3.3 \mathrm{~W}$; whereas in American frequencies it is $4 \mathrm{~W}$. The power transmission coefficient is inferred from the simulation of the return loss of the antenna, using as port impedance that of the chip. The tag gain is also obtained from simulation; hence the theoretical read range can be calculated.

The experimental setup consists of a N5182A vector signal generator which creates RFID frames. Such generator is connected to a TEM cell by means of a circulator. The tag under test is located inside the TEM cell and it is excited by the frame created by the generator. Then the tag sends a backscatter signal to a N9020A signal analyzer through the circulator. The RFID frame frequency is swept with a specific power. Once the operation frequencies are identified, the output power is decreased until the tag stops working. Finally, a probe is placed into the TEM cell in order to determine the incident electric field intensity $E_{0}$ at each 


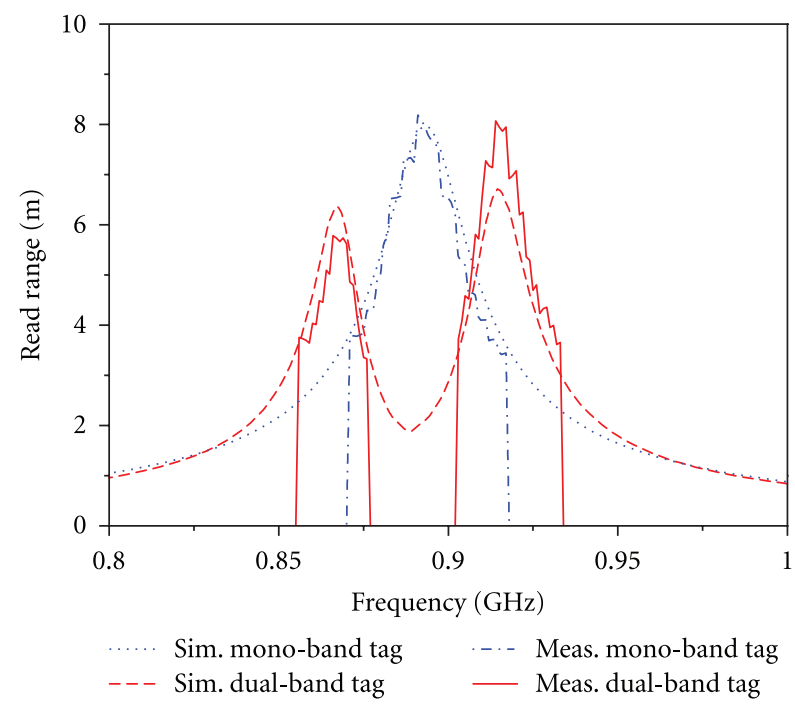

(a)

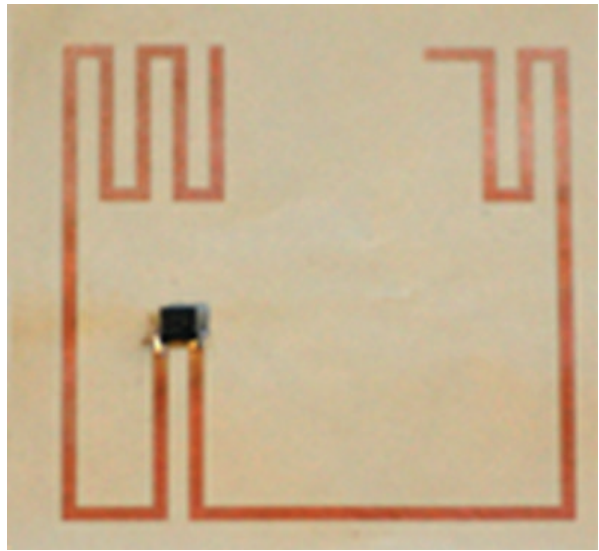

(b)

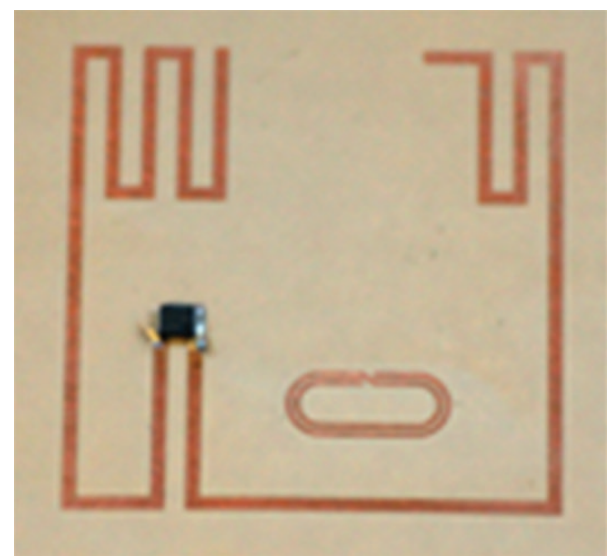

(c)

Figure 13: (a) Simulated and measured read ranges of the monoband and dual-band MLA RFID tags, and fabricated monoband (b) and dual-band (c) MLA RFID tags.

frequency, which is related to the received power by the chip according to

$$
P_{\text {chip }}=S A_{\text {ef }} \tau=\frac{\left|E_{0}\right|^{2}}{2 \eta} \frac{\lambda^{2} G_{r}}{4 \pi} \tau,
$$

where $S$ is the incident power density, $A_{\text {ef }}$ is the effective area of the tag antenna, and $\eta$ is the free-space wave impedance (which is equivalent to $120 \pi \Omega$ ). The measured read range can be inferred by introducing (2) in (1), resulting in

$$
r=\frac{\sqrt{60 \mathrm{EIRP}}}{E_{0}} .
$$

As indicated before, the EIRP European value is lower than the USA counterpart, so the read range in Europe would be roughly reduced by a 0.9 factor for the same incident electric field intensity.

The fabricated tags, as well as the simulated and measured read ranges, are depicted in Figure 13, where it can be seen that the read range obtained in the dual-band tags (at the frequencies of interest) is superior to that of the monoband tag. The read range of the monoband MLA tag is roughly $4 \mathrm{~m}$ at the frequencies of interest, whereas almost $6 \mathrm{~m}$ and $8 \mathrm{~m}$ at the European and USA frequency bands, respectively, are achieved by means of the designed dual-band MLA. This enhancement in the read range is due to an improved matching between the antenna and the integrated circuit, since it has been verified by simulation that the radiation efficiency of the monoband MLA is almost constant from $867 \mathrm{MHz}$ to $950 \mathrm{MHz}$. In fact, if it was possible to achieve a perfect matching between the monoband antenna and the integrated circuit in all the band of interest, the obtained read range would be around $8 \mathrm{~m}$ at all frequencies. Nevertheless, this assumption is not possible due to the particularities of the chip impedance.

The perturbation method reported above can also be applied to folded dipole RFID tag antennas [42]. Figure 14 depicts a prototype, fabricated on the Rogers RO3010 with 


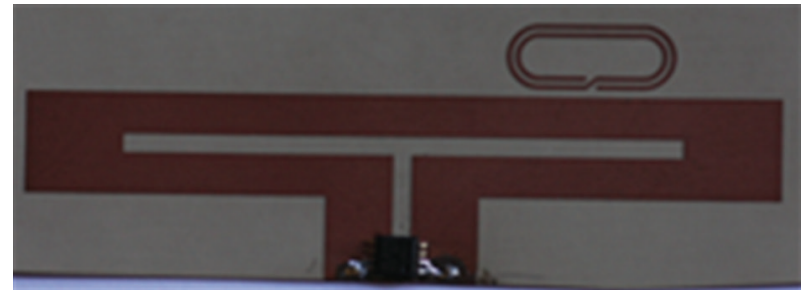

FIgUre 14: Photograph of the designed dual-band tag based on a folded dipole antenna.

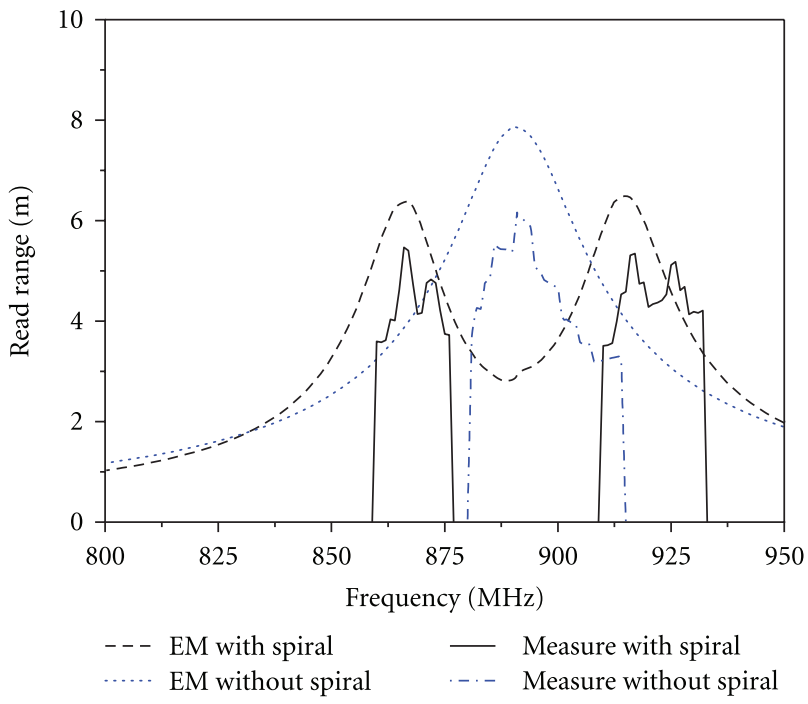

FIGURE 15: EM simulation and measurement of the read range of the tag shown in Figure 13, compared to that of the tag without SR.

dielectric constant $\varepsilon_{r}=10.2$ and thickness $h=0.25 \mathrm{~mm}$. The dimensions are $62.7 \mathrm{~mm} \times 17.9 \mathrm{~mm}$. The simulated and measured read ranges are depicted in Figure 15 and compared to those of the tag without the presence of the SR. Again, the dual-band functionality at the regulated RFID European and USA frequency bands is achieved.

We would like to mention that in the designed RFID tags, the resonator frequency is set at the intermediate frequency $(891 \mathrm{MHz})$, and as a consequence, the resonator impact on the antenna radiation efficiency can be neglected at the frequency bands of interest (867 MHz and $915 \mathrm{MHz}$ ).

\section{Conclusions}

In conclusion, two different approaches for the implementation of multiband printed antennas have been reviewed: one of them consisting on the introduction of series connected OCSRRs in the arms of printed dipole or printed monopole antennas; the other one based on a perturbation method achieved by loading printed antennas, such as meander line antennas (MLAs) or folded dipoles, with spiral resonators (SRs). The former approach has been revealed to be useful for personal area networks (PANs) and wireless local area networks (WLANs); the second one is of interest in the field of UHF-RFID. In both cases, the multiband functionality has been demonstrated through the fabrication and characterization of several prototype devices.

\section{Acknowledgments}

This work has been supported by Spain-MICIIN (Project contracts TEC2010-17512 METATRANSFER and CSD200800066) and Spain MITyC through the Projects TSI-0201002009-778 and TSI-020100-2010-493. Thanks are also given to the Catalan Government for giving support through Project 2009SGR-421.

\section{References}

[1] G. V. Eleftheriades and K. G. Balmain, Eds., NegativeRefraction Metamaterials: Fundamental Principles and Applications, John Wiley \& Sons, New York, NY, USA, 2005.

[2] C. Caloz and T. Itoh, Electromagnetic Metamaterials: Transmission Line Theory and Microwave Applications, John Wiley \& Sons, New York, NY, USA, 2006.

[3] N. Engheta and R. W. Ziolkowski, Metamaterials: Physics and Engineering Explorations, John Wiley \& Sons, New York, NY, USA, 2006.

[4] R. Marques, F. Martín, and M. Sorolla, Metamaterials with Negative Parameters: Theory, Design and Microwave Applications, John Wiley \& Sons, New York, NY, USA, 2008.

[5] F. Capolino, Ed., Metamaterials Handbook, CRC Press, Boca Raton, Fla, USA, 2009.

[6] L. Solymar and E. Shamonina, Waves in Metamaterials, Oxford University Press, Oxford, UK, 2009.

[7] T. J. Cui, D. R. Smith, and R. Liu, Eds., Metamaterials: Theory, Design and Applications, Springer, New York, NY, USA, 2010.

[8] W. Cai and V. Shalaev, Optical Metamaterials: Fundamentals and Applications, Springer, New York, NY, USA, 2010.

[9] G. Shvets and I. Sukerman, Eds., Plasmonics and Plasmonics Metamaterials: Analysis and Applications, World Scientific, 2011.

[10] Y. Hao and R. Mittra, FDTD Modelling of Metamaterials: Modeling and Applications, Artech House, 2009.

[11] D. R. Smith, W. J. Padilla, D. C. Vier, S. C. Nemat-Nasser, and S. Schultz, "Composite medium with simultaneously negative permeability and permittivity," Physical Review Letters, vol. 84, no. 18, pp. 4184-4187, 2000.

[12] J. B. Pendry, A. J. Holden, D. J. Robbins, and W. J. Stewart, "Magnetism from conductors and enhanced nonlinear phenomena," IEEE Transactions on Microwave Theory and Techniques, vol. 47, no. 11, pp. 2075-2084, 1999.

[13] V. G. Veselago, "The electrodynamics of substances with simultaneously negative values of $\varepsilon$ and $\mu$," Soviet Physics Uspekhi, vol. 10, pp. 509-514, 1968.

[14] A. K. Iyer and G. V. Eleftheriades, "Negative refractive index metamaterials supporting 2-D waves," in Proceedings of the IEEE MSS-S International Microwave Symposium Digest, pp. 1067-1070, June 2002.

[15] A. A. Oliner, "A periodic-structure negative-refractive-index medium without resonant elements," in Proceedings of the IEEE-AP-S USNC/URSI National Radio Science Meeting: URSI Digest, p. 41, San Antonio, Tex, USA, June 2002.

[16] C. Caloz and T. Itoh, "Application of the transmission line theory of left-handed (LH) materials to the realization of a microstrip "LH line"," in Proceedings of the IEEE Antennas and Propagation Society International Symposium, pp. 412415, Los Angeles, Calif, USA, June 2002. 
[17] F. Martín, J. Bonache, F. Falcone, M. Sorolla, and R. Marqués, "Split ring resonator-based left-handed coplanar waveguide," Applied Physics Letters, vol. 83, no. 22, pp. 4652-4654, 2003.

[18] F. Falcone, F. Martin, J. Bonache, R. Marqués, and M. Sorolla, "Coplanar waveguide structures loaded with split-ring resonators," Microwave and Optical Technology Letters, vol. 40, no. 1, pp. 3-6, 2004.

[19] M. Durán-Sindreu, A. Vélez, G. Sisó et al., "Recent advances in metamaterial transmission lines based on split rings," Proceedings of the IEEE, vol. 99, pp. 1701-1710, 2011.

[20] R. Marqués, F. Medina, and R. Rafii-El-Idrissi, "Role of bianisotropy in negative, permeability and left-handed metamaterials," Physical Review B, vol. 65, no. 14, Article ID 144440, pp. 1-6, 2002.

[21] F. Falcone, T. Lopetegi, J. D. Baena, R. Marqués, F. Martín, and M. Sorolla, "Effective negative- $\varepsilon$ stopband microstrip lines based on complementary split ring resonators," IEEE Microwave and Wireless Components Letters, vol. 14, no. 6, pp. 280-282, 2004.

[22] F. Falcone, T. Lopetegi, M. A. G. Laso et al., "Babinet principle applied to the design of metasurfaces and metamaterials," Physical Review Letters, vol. 93, no. 19, Article ID 197401, 2004.

[23] J. D. Baena, J. Bonache, F. Martín et al., "Equivalent-circuit models for split-ring resonators and complementary splitring resonators coupled to planar transmission lines," IEEE Transactions on Microwave Theory and Techniques, vol. 53, no. 4, pp. 1451-1460, 2005.

[24] J. Martel, R. Marqués, F. Falcone et al., "A new LC series element for compact bandpass filter design," IEEE Microwave and Wireless Components Letters, vol. 14, no. 5, pp. 210-212, 2004.

[25] A. Vélez, F. Aznar, J. Bonache, M. C. Velázquez-Ahumada, J. Martel, and F. Martín, "Open Complementary Split Ring Resonators (OCSRRs) and their application to wideband cpw band pass filters," IEEE Microwave and Wireless Components Letters, vol. 19, no. 4, pp. 197-199, 2009.

[26] M. Durán-Sindreu, A. Vélez, F. Aznar, G. Sisó, J. Bonache, and F. Martín, "Applications of open split ring resonators and open complementary split ring resonators to the synthesis of artificial transmission lines and microwave passive components," IEEE Transactions on Microwave Theory and Techniques, vol. 57, no. 12, pp. 3395-3403, 2009.

[27] J. D. Baena, R. Marqués, F. Medina, and J. Martel, "Artificial magnetic metamaterial design by using spiral resonators," Physical Review B, vol. 69, no. 1, Article ID 014402, pp. 1-5, 2004.

[28] F. Falcone, F. Martín, J. Bonache et al., "Stop-band and bandpass characteristics in coplanar waveguides coupled to spiral resonators," Microwave and Optical Technology Letters, vol. 42, no. 5, pp. 386-388, 2004.

[29] F. Bilotti, A. Toscano, and L. Vegni, "Design of spiral and multiple split-ring resonators for the realization of miniaturized metamaterial samples," IEEE Transactions on Antennas and Propagation, vol. 55, no. 8, pp. 2258-2267, 2007.

[30] F. Bilotti, A. Alu, and L. Vegni, "Design of miniaturized metamaterial patch antennas with $\mu$-negative loading," IEEE Transactions on Antennas and Propagation, vol. 56, no. 6, pp. 1640-1647, 2008.

[31] C. Caloz, T. Itoh, and A. Rennings, "CRLH metamaterial leaky-wave and resonant antennas," IEEE Antennas and Propagation Magazine, vol. 50, no. 5, pp. 25-39, 2008.

[32] A. Erentok and R. W. Ziolkowski, "A dual-band efficient metamaterial-inspired electrically-small magnetic-based antenna," in Proceedings of the IEEE Antennas and Propagation Society International Symposium (AP-S '07), pp. 1877-1880, Honolulu, Hawaii, USA, June 2007.

[33] J. Zhu and G. V. Eleftheriades, "Dual-band metamaterialinspired small monopole antenna for WiFi applications," Electronics Letters, vol. 45, no. 22, pp. 1104-1106, 2009.

[34] F. J. Herraiz-Martínez, L. E. García-Muñoz, D. GonzálezOvejero, V. González-Posadas, and D. Segovia-Vargas, "Dualfrequency printed dipole loaded with split ring resonators," IEEE Antennas and Wireless Propagation Letters, vol. 8, pp. 137-140, 2009.

[35] F. J. Herraiz-Martínez, L. E. García-Muñoz, D. GonzálezOvejero, V. González-Posadas, and D. Segovia-Vargas, "Dualfrequency printed dipole loaded with split ring resonators," IEEE Antennas and Wireless Propagation Letters, vol. 8, pp. 137-140, 2009.

[36] J. Montero-de-Paz, E. Ugarte-Muñoz, F. J. Herraiz-Martínez, V. Gonzáalez-Posadas, L. E. García-Muñoz, and D. SegoviaVargas, "Multifrequency self-diplexed single patch antennas loaded with split ring resonators," Progress in Electromagnetics Research, vol. 113, pp. 47-66, 2011.

[37] F. J. Herraiz-Martínez, F. Paredes, G. Zamora, F. Martín, and J. Bonache, "Dual-band printed dipole antenna loaded with open complementary split-ring resonators (OCSRRs) for wireless applications," Microwave and Optical Technology Letters, vol. 54, no. 4, pp. 1014-1017, 2012.

[38] F. J. Herraiz-Martínez, G. Zamora, F. Paredes, F. Martín, and J. Bonache, "Multiband printed monopole antennas loaded with open complementary split ring resonators for PANs and WLANs," IEEE Antennas and Wireless Propagation Letters, vol. 10, pp. 1528-1531, 2011.

[39] Z. Živković and A. Šarolić, "Gain and antenna factor measurements of broadband biconical dipole in the GTEM cell," in Proceedings of the 52nd International Symposium (ELMAR '10), pp. 297-300, Zadar, Cratia, September 2010.

[40] F. Paredes, G. Zamora, J. Bonache, and F. Martín, "Dual-band impedance-matching networks based on split-ring resonators for applications in RF identification (RFID)," IEEE Transactions on Microwave Theory and Techniques, vol. 58, no. 5, pp. 1159-1166, 2010.

[41] F. Paredes, G. Zamora, F. J. Herraiz-Martínez, F. Martín, and J. Bonache, "Dual-band UHF-RFID tags based on meander line antennas loaded with spiral resonators," IEEE Antennas and Wireless Propagation Letters, vol. 10, pp. 768-771, 2011.

[42] F. Paredes, G. Zamora, F. Javier Herraiz-Martínez, F. Martín, and J. Bonache, "Dual-band RFID Tags based on Folded Dipole Antennas Loaded with Spiral Resonators," in Proceedings of the IEEE International Workshop on Antenna Technology: Small Antennas and Unconventional Applications (IWAT '12), Tucson, Ariz, USA, March 2012. 

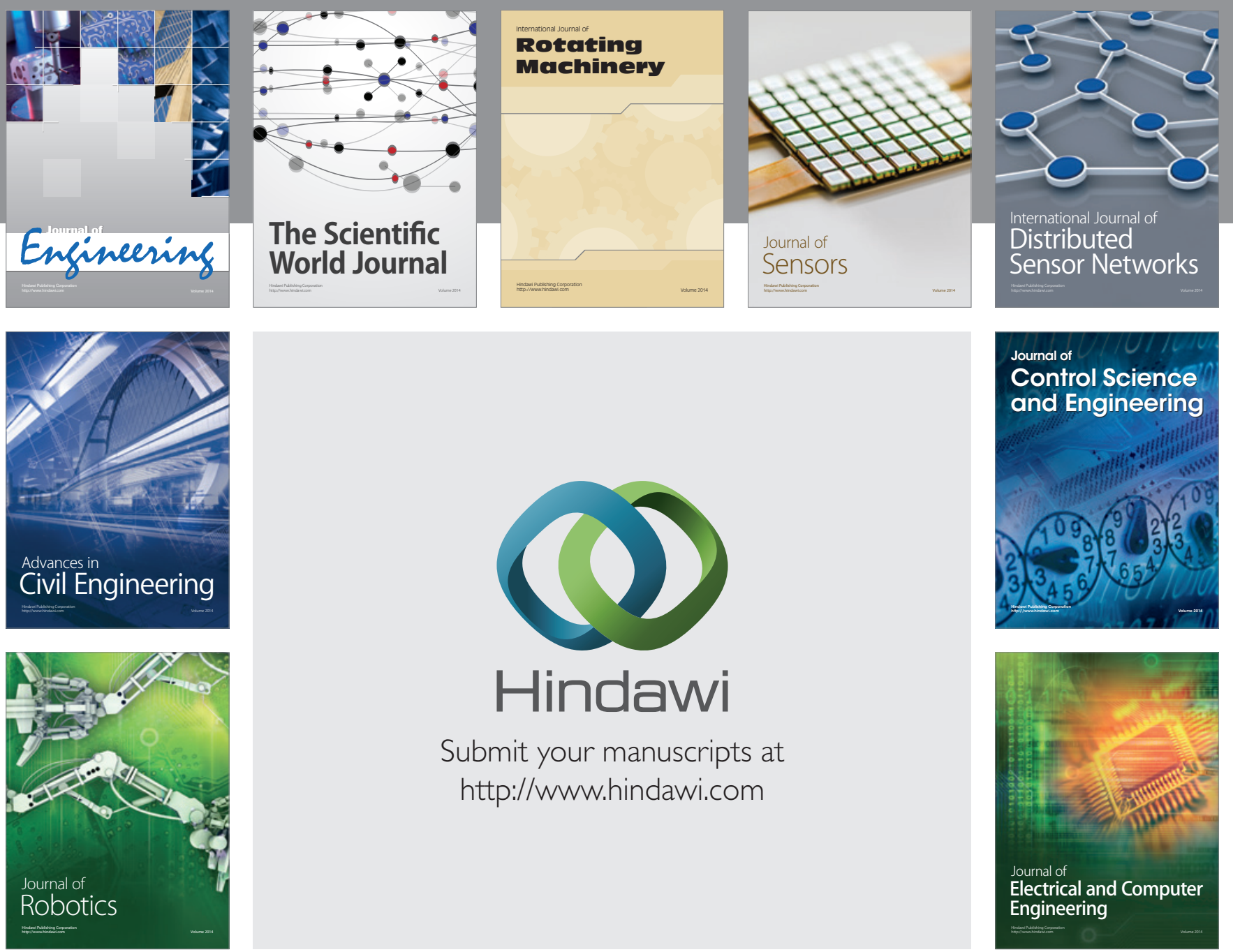

Submit your manuscripts at

http://www.hindawi.com
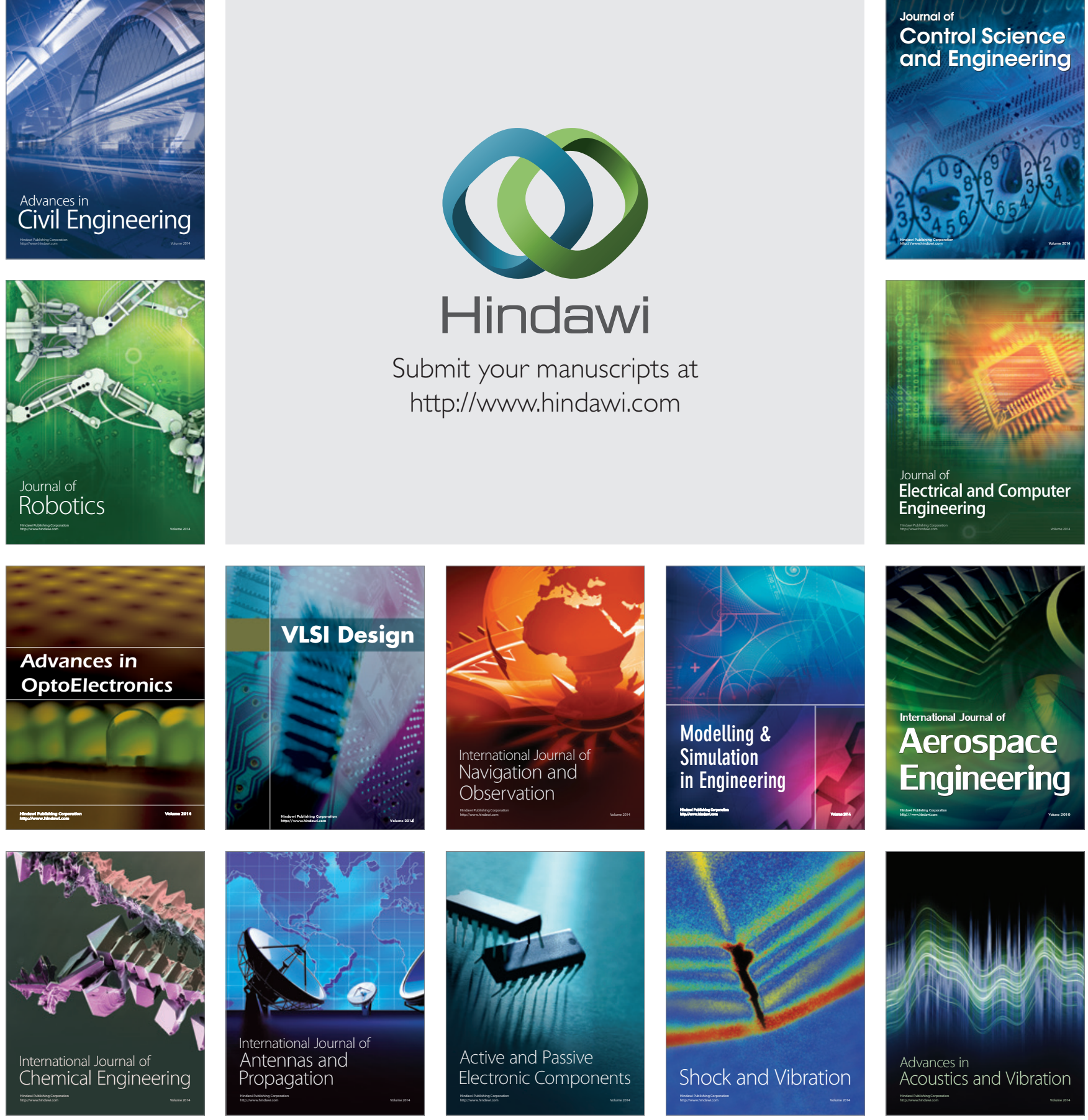